\title{
Evaluation of a Loop-Mediated Isothermal Amplification Technique for the Rapid Visual Detection of Hepatozoon canis Infection
}

\author{
Manraj Deep Singh $^{1} \cdot$ Harkirat Singh ${ }^{1} \cdot$ Nirbhay Kumar Singh $^{1} \cdot$ Niraj Kumar Singh $^{2} \cdot$ Naresh Kumar Sood $^{3}$. \\ Shitanshu Shekar Rath ${ }^{1}$
}

Received: 14 June 2019 / Accepted: 6 November 2019 / Published online: 15 November 2019

(c) Witold Stefański Institute of Parasitology, Polish Academy of Sciences 2019

\begin{abstract}
Background Laboratory diagnosis of Hepatozoon canis infection is tedious, especially in chronic and/or latent infections. Purpose The study was planned to develop a simple read out loop mediated isothermal amplification (LAMP) assay targeting a partial $18 \mathrm{~S}$ rRNA gene of $H$. canis with naked eye visualisation of LAMP products.

Methods A LAMP assay was employed to assess the DNA amplification by adding SYBR Green I dye for naked eye inspection of DNA accumulating in reaction tubes. Positive amplification was read through observation of change in colour of reaction mixture following addition of dye. The visual results were further verified with those of agarose gel electrophoresis. Genomic DNA of other haemoparasites of dog viz. Babesia vogeli, B. gibsoni, Ehrlichia canis and Trypanosoma evansi along with no-template control were used to determine the specificity of assay.

Results Among the 109 blood samples presented at Small Animal Clinics, Teaching Veterinary Clinical Complex, Guru Angad Dev Veterinary and Animal Sciences University, Ludhiana, Punjab (India) tested, 39 revealed colour change from orange to green indicating positive reaction while 70 were negative as revealed by no colour change. The results of visual inspection were comparable to those obtained by agarose gel electrophoresis. The LAMP primers specifically amplified H. canis DNA, whereas no amplification was detected in DNA samples of other haemoparasites and no-template control revealing specificity of the assay. The diagnostic sensitivity and specificity $(95 \% \mathrm{CI})$ of visual LAMP assay with respect to microscopy in detection of $H$. canis varied from $100 \%$ (15.81-100.00\%) and 65.42\% (55.61-74.35\%), respectively.

Conclusion The present investigation has developed a specific and rapid LAMP assay for the detection of $H$. canis, using SYBR Green I dye, which has practical applications for the screening of field samples.
\end{abstract}

Keywords Hepatozoon canis · LAMP assay · SYBR Green I dye · Visual inspection

\section{Introduction}

Harkirat Singh

drharkiratsingh@hotmail.com

1 Department of Veterinary Parasitology, College of Veterinary Science, Guru Angad Dev Veterinary and Animal Sciences University, Ludhiana, Punjab 141004, India

2 Department of Animal Biotechnology, College of Animal Biotechnology, Guru Angad Dev Veterinary and Animal Sciences University, Ludhiana, Punjab 141004, India

3 Department of Teaching Veterinary Clinical Complex, College of Veterinary Science, Guru Angad Dev Veterinary and Animal Sciences University, Ludhiana, Punjab 141004, India
Hepatozoon canis is one of the most common tick transmitted apicomplexan protozoan parasite with worldwide distribution [1,2]. The parasite is transmitted by ingestion of the brown dog tick, Rhipicephalus sanguineus sensu lato containing the mature oocysts [3]. Generally the infections are asymptomatic to mild, but may also become severe and fatal [4]. The clinical findings including anorexia, lethargy, fever, cachexia, pale mucous membranes and hind limb paralysis [5].

On diagnostic front, conventional parasitological examination viz. detection of ellipsoidal gamonts within the neutrophils or monocytes, in stained blood smears by microscopy and/or histopathological visualization of meronts or monozoic cysts in tissues are employed [6]. Serodiagnostic 
tests, like enzyme linked immunosorbent assay and indirect fluorescent antibody test have also been utilized for detection of parasite specific antibodies [7, 8]. In recent times, nucleic acid based diagnostic techniques viz. polymerase chain reaction (PCR), real time-PCR assay and sequence analysis have been utilized worldwide for the diagnosis of $H$. canis infection and specification of the isolates, respectively $[2,9,10]$ as they offer high levels of specificity and sensitivity in both, hosts (dogs) as well as vectors (ticks) [2, 11, 12].

The loop-mediated isothermal amplification (LAMP) method in the last decade has been used for early and sensitive diagnosis of various infectious agents [13-16]. The assay has advantages over other molecular tests in terms of simplicity, higher throughput amplification efficiency and ease of evaluation of results by visualization of the turbidity in positive reactions [17]. In our previous study, a LAMP assay was developed, for the first time, targeting the partial 18S rRNA gene of H. canis which revealed high levels of sensitivity, specificity and threshold detection over the traditional PCR assay and microscopy when applied on blood samples collected from dogs [16]. The present study was planned to develop a simple read out LAMP technology by naked eye visualization using SYBR Green I dye for interpretation of the LAMP results.

\section{Materials and Methods}

\section{Ethical Guidelines}

Approval and necessary guidelines of Institute Animal Ethics Committee (IAEC) was obtained GADVASU/2017/ IAEC/39/12 vide Memo no. IAEC/2017/734-760 dated 20.03.2017 for conduction of the study.

\section{Samples}

The blood samples $(n=109)$ were collected randomly from the dogs presented in the Small Animal Clinics, Teaching Veterinary Clinical Complex, Guru Angad Dev Veterinary and Animal Sciences University, Ludhiana, Punjab (India). These animals were suspected for haemoprotozoan infections and blood collected for conduction of diagnostic tests was used for DNA isolation in the study.

\section{LAMP Assay}

The LAMP assay standardized in our previous study was employed on the isolated whole blood genomic DNA from the collected blood samples [16]. In brief, the reaction mixture consisted of 5 pmol of each outer primer (F3 and B3), $50 \mathrm{pmol}$ of each inner primer (FIP and BIP), $0.6 \mathrm{M}$ betaine (Sigma, USA), $6 \mathrm{mM} \mathrm{MgSO}_{4}$ (New England Biolabs, UK),
$1.6 \mathrm{mM}$ dNTP mix (MBI Fermentas, USA), $1 \times$ ThermoPol reaction buffer $\left(20 \mathrm{mM}\right.$ Tris- $\mathrm{HCl}, 10 \mathrm{mM}\left(\mathrm{NH}_{4}\right)_{2} \mathrm{SO}_{4}$, $10 \mathrm{mM} \mathrm{KCl}, 2 \mathrm{mM} \mathrm{MgSO}_{4}, 0.1 \%$ Triton X-100) and $1 \mu \mathrm{L}$ of target DNA. The reaction mixture was heated at $95{ }^{\circ} \mathrm{C}$ for $5 \mathrm{~min}$, chilled on ice and subsequently $1 \mu \mathrm{L}$ (8U) Bst DNA polymerase large fragment (New England Biolabs, UK) was added. The amplification reaction was carried out at $55^{\circ} \mathrm{C}$ for $90 \mathrm{~min}$ and terminated by incubating at $80{ }^{\circ} \mathrm{C}$ for $2 \mathrm{~min}$. Genomic DNA isolated from an infection free puppy and nuclease free water were used as negative and no-template control, respectively, while DNA isolated from a microscopically confirmed $H$. canis positive sample was used as positive control in all the runs.

\section{Naked Eye Visualization of LAMP Products}

The DNA amplification was assessed by adding $1.0 \mu \mathrm{L}$ of the fluorescent intercalating SYBR Green I (Invitrogen) dye for naked eye inspection of DNA accumulating in the reaction tubes by visual fluorescence. The positive amplification was read through observation of change in colour of the reaction mixture following addition of dye to the tube. The results were further verified by electrophoresis of LAMP products in $2 \%$ ethidium bromide-stained agarose gel (Agarose Low EEO, SRL), and visualized using InGenius ${ }^{\circledR}$ Gel Documentation System (Syngene, UK). The specificity of the visual LAMP assay was determined by utilizing the genomic DNA extracted from whole blood of dogs infected with other haemoparasites viz. B. vogeli, B. gibsoni, E. canis and T. evansi along with no-template control. Further, the results of visual LAMP assay were compared with those of microscopy to determine the diagnostic sensitivity and specificity of the assay.

\section{Statistical Analysis}

The data obtained from visual LAMP assay and microscopy (gold standard test) were analyzed with the help of SAS software (SAS 9.3 Version). McNemar's test $P$ value, specificity and sensitivity with $95 \%$ confidence interval (CI) were calculated.

\section{Results}

To evaluate the usefulness of the optimized LAMP assay as a rapid diagnostic tool, the whole blood genomic DNA extracted from the collected blood samples $(n=109)$ were tested. An observation of colour change following the addition of $1 \mu \mathrm{L}$ of SYBR Green I dye was visually detected in the PCR tubes. In case of positive amplification, the original orange colour of the dye changed into green $(n=39)$ while in case of no amplification, the original orange colour of the 
Fig. 1 Field application of visual LAMP assay for detection of H. canis. Positives reactions: tube no. 2,3 , and 12 . Negative reactions: tube no. 1 , $4-11$, and 13

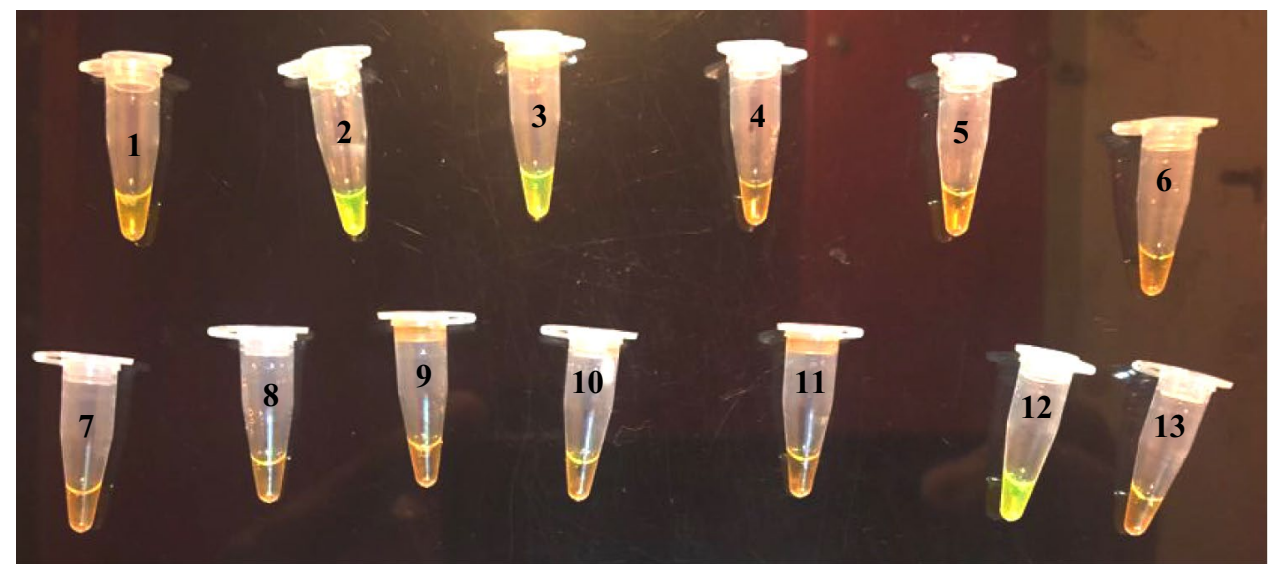

detected in DNA samples from dogs infected with $B$. vogeli, B. gibsoni, E. canis, T. evansi, and no-template control revealing specificity of the assay (Fig. 3).

The developed visual LAMP assay detected significantly higher number of samples positive for $H$. canis in comparison to microscopy $\left(\chi^{2}\right.$ value $=35.027 ; P$ value $\left.\leq 0.0001\right)$. The diagnostic sensitivity and specificity $(95 \% \mathrm{CI})$ of visual LAMP assay with respect to microscopy in detection of $H$. canis varied from $100 \%$ (15.81-100.00\%) and $65.42 \%$ (55.61-74.35\%), respectively. In the present study the LAMP assay seemed to be more sensitive than microscopy as those samples of blood $(n=37)$ which were negative in microscopy were also amplified for the presence of parasite DNA.

\section{Discussion}

Fig. 2 Field application of LAMP assay for detection of $H$. canis. Lane M: Generuler ${ }^{\mathrm{TM}} 100$ bp Ladder. Lane P: positive control. Lane 7: negative control. Lane 1-6, 8: field samples

dye was retained $(n=70)$, revealing $35.77 \%$ positivity for $H$. canis infection (Fig. 1). It was observed that results of the agarose gel electrophoresis for the same samples were comparable with that of visual examination as revealed by characteristic ladder-like multiple bands in the positive samples (Fig. 2). The LAMP primers specifically amplified $H$. canis DNA (positive control), whereas no amplification was
To facilitate the application of LAMP assay, monitoring of amplification can be carried out with naked eye inspection either in the form of visual turbidity or visual fluorescence [18]. However, the techniques relying on indirect detection methods, i.e. turbidity and colorimetry, may not be able to distinguish between real and false positives under some unexpected cases when non-specific amplification occurs [19]. In this regard, the monitoring may be done by use of fluorescent dyes viz. SYBR Green I. In the presence of sufficient amount of double stranded DNA, the color of SYBR
Fig. 3 Specificity of visual LAMP assay for detection of $H$. canis. Tube 1: negative control. Tube 2: $H$. canis DNA. Tube 3: B. vogeli DNA. Tube 4: $B$. gibsoni DNA. Tube 5: E. canis DNA. Tube 6: T. evansi DNA

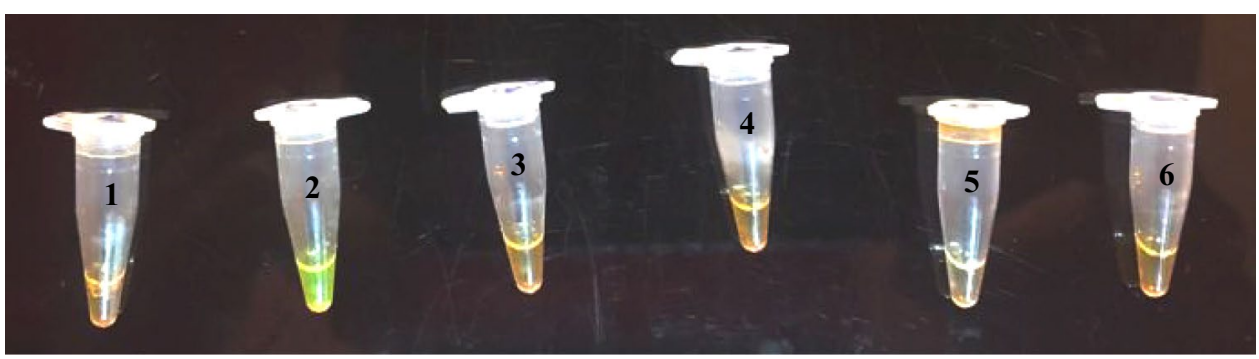


Green I turns from orange to green which is apparent under natural as well as ultraviolet light $[19,20]$ making it ideal for easy monitoring through naked eye. Furthermore, the employment of SYBR Green I lead to increased sensitivity when compared with visual turbidity measurements as per Zhang et al. [20] and Soli et al. [21].

In practice, the visual inspection for amplification is performed through observation of color change by adding $1 \mu \mathrm{L}$ of SYBR Green I to the tube and the result of the LAMP reaction can be monitored by the naked eye at the end point [20-23]. Although, the risk of contamination of amplicons may increase because of the need to open the reaction tubes to add the dye, however, opening the reaction tube after amplification with care to prevent carry-over contamination can be done to minimize the risk. On the other hand, agarose gel electrophoresis is a conventional method for monitoring the LAMP amplicons directly $[13,18,19$, 24], and even serves as a "gold standard" methodology in many situations. The results are interpreted as appearance of ladder-like banding in positive reaction tube under ultraviolet (UV) gel imaging analysis system. However, ethidium bromide, used in gel electrophoresis, may act as mutagen, carcinogen, or teratogen, though this depends on the organism exposed and the circumstances of exposure [25]. Additionally, the method possesses a risk of cross-contamination and also relatively long turnaround times [26]. Also, the requirement for electrophoresis apparatus and UV detection limits the suitability for field applications.

\section{Conclusions}

In the current investigation, a LAMP assay targeting the partial 18S rRNA gene of $H$. canis was evaluated for its application in field conditions, by monitoring the amplification with naked eye inspection in the form of visual fluorescence using the fluorescent intercalating dye SYBR Green I.

Therefore, it may be concluded that a simple and rapid LAMP assay with use of SYBR Green I dye eliminates the agarose gel electrophoresis used for documentation of results and thus is a rapid and time saving simple diagnostic technique for detection of $H$. canis infection in dogs. Furthermore, the LAMP assay can be employed as a simple read out technology (naked eye visualisation of LAMP products) in the field for routine examination, where sophisticated and high-end equipments are not feasible.

\footnotetext{
Acknowledgements The authors are very grateful to The Dean, Postgraduate Studies, Guru Angad Dev Veterinary and Animal Sciences University, Ludhiana, Punjab for providing the necessary facilities. Thanks are also due to the faculty of Department of Veterinary Medicine and Teaching Veterinary Clinical Complex for the smooth conduct of study.
}

\section{Compliance with ethical standards}

Conflict of interest The authors declare that they have no conflict of interest.

\section{References}

1. Otranto D, Dantas-Torres F (2010) Canine and feline vector-borne diseases in Italy: current situation and perspectives. Parasite Vectors $3: 2$

2. Singh K, Singh H, Singh NK, Kashyap N, Sood NK, Rath SS (2017) Molecular prevalence, risk factors assessment and haemato-biochemical alterations in hepatozoonosis in dogs from Punjab, India. Comp Immunol Microbiol Infect Dis 55:53-58

3. Nava S, Estrada-Peña A, Petney T, Beati L, Labruna MB, Szabó MP, Venzal JM, Mastropaolo M, Mangold AJ, Guglielmone AA (2015) The taxonomic status of Rhipicephalus sanguineus (Latreille, 1806). Vet Parasitol 208:2-8

4. Gavazza A, Bizzeti M, Papini R (2003) Observations on dogs found naturally infected with Hepatozoon canis in Italy. Revue de Médecine Vétérinaire 154:565-571

5. Baneth G, Weigler B (1997) Retrospective case-control study of hepatozoonosis in dogs in Israel. J Vet Intern Med 11:365-370

6. Baneth G, Shkap V (2003) Monozoic cysts of Hepatozoon canis. J Parasitol 89:379-381

7. Shkap V, Baneth G, Pipano E (1994) Circulating antibodies to Hepatozoon canis demonstrated by immunofluorescence. J Vet Diagn Investig 6:121-123

8. Mylonakis ME, Leontides L, Gonen L, Billinis C, Koutinas AF, Baneth G (2005) Anti-Hepatozoon canis serum antibodies and gamonts in naturally-occurring canine monocytic ehrlichiosis. Vet Parasitol 129:229-233

9. Abd Rani PAM, Irwin PJ, Coleman GT, Gatne M, Traub RJ (2011) A survey of canine tick-borne diseases in India. Parasite Vectors $4: 141-148$

10. Aktas M, Özübek S, Altay K, Balkaya I, Utuk AE, Kırbas A, Simsek S, Dumanli N (2015) A molecular and parasitological survey of Hepatozoon canis in domestic dogs in Turkey. Vet Parasitol 209:264-267

11. Latrofa MS, Dantas-Torres F, Giannelli A, Otranto D (2014) Molecular detection of tick-borne pathogens in Rhipicephalus sanguineus group ticks. Ticks Tick Borne Dis 5:943-946

12. Singh K, Singh H, Singh NK, Kashyap N, Rath SS (2017) Molecular prevalence of Hepatozoon canis infection in dog tick, Rhipicephalus sanguineus, from Punjab, India. J Anim Res 7:401-404

13. Notomi T, Okayama $\mathrm{H}$, Masubuchi $\mathrm{H}$, Yonekawa $\mathrm{T}$, Watanabe $\mathrm{K}$, Amino N, Hase T (2000) Loop-mediated isothermal amplification of DNA. Nucleic Acids Res 28:E63

14. Karanis P, Ongerth J (2009) LAMP - a powerful and flexible tool for monitoring microbial pathogens. Trends Parasitol 25:498-499

15. Mandal M, Banerjee PS, Kumar S, Ram H, Garg R, Pawde AM (2015) Development of loop-mediated isothermal amplification (LAMP) for detection of Babesia gibsoni infection in dogs. Vet Parasitol 209:50-55

16. Singh MD, Singh H, Singh NK, Singh NK, Kashyap N, Sood NK, Rath SS (2019) Development of loop-mediated isothermal amplification (LAMP) assay for detection of Hepatozoon canis infection in dogs. Ticks Tick Borne Dis 10:371-376

17. Mori Y, Nagamine K, Tomita N, Notomi T (2001) Detection of loop-mediated isothermal amplification reaction by turbidity derived from magnesium pyrophosphate formation. Biochem Biophys Res Commun 289:150-154 
18. Parida M, Sannarangaiafh S, Dash PK, Rao PV, Morita K (2008) Loop mediated isothermal amplification (LAMP): a new generation of innovative gene amplification technique; perspectives in clinical diagnosis of infectious diseases. Rev Med Virol 18:407-421

19. Lee D, Mura ML, Allnutt TR, Powell W (2009) Detection of genetically modified organisms (GMOs) using isothermal amplification of target DNA sequences. BMC Biotechnol 9:7

20. Zhang Y, Shan X, Shi L, Lu X, Tang S, Wang Y, Li Y, Alam MJ, Yan H (2012) Development of a fimY-based loop-mediated isothermal amplification assay for detection of Salmonella in food. Food Res Int 45:1011-1015

21. Soli KW, Kas M, Maur T, Umezaki M, Morita A, Siba PM, Greenhill AR, Horwood PF (2013) Evaluation of colorimetric detection methods for Shigella, Salmonella, and Vibrio cholerae by loopmediated isothermal amplification. Diagn Microbiol Infect Dis 77:321-323

22. Iwamoto T, Sonobe T, Hayashi K (2003) Loop-mediated isothermal amplification for direct detection of Mycobacterium tuberculosis complex, M. avium, and M. intracellulare in sputum samples. J Clin Microbiol 41:2616-2622
23. Le TH, Nguyen NTB, Truong NH, De NV (2012) Development of mitochondrial loop-mediated isothermal amplification for detection of the small liver fluke Opisthorchis viverrini (Opisthorchiidae; Trematoda; Platyhelminthes). J Clin Microbiol 50:1178-1184

24. Tanner NA, Evans TC Jr. (2014) Loop-mediated isothermal amplification for detection of nucleic acids. Current Protoc Mol Biol. https://doi.org/10.1002/0471142727.mb1514s105

25. Tomita N, Mori Y, Kanda H, Notomi T (2008) Loop-mediated isothermal amplification (LAMP) of gene sequences and simple visual detection of products. Nat Protoc 3:877-882

26. Zhang X, Qu K, Li Q, Cui Z, Zhao J, Sun X (2011) Recording the reaction process of loop-mediated isothermal amplification (LAMP) by monitoring the voltammetric response of $2^{\prime}$-deoxyguanosine 5'-triphosphate. Electroanalysis 23:2438-2445

Publisher's Note Springer Nature remains neutral with regard to jurisdictional claims in published maps and institutional affiliations. 